\title{
TECNOLOGÍAS LITERARIAS: LA ORALIDAD EN LA POESÍA DIGITAL
}

\author{
María Teresa Vilariño Picos \\ Universidade de Santiago de Compostela
}

La voz es un querer-decir y una voluntad de existencia.

P. Zumthor

Mobile textscapes are, metaphorically speaking. J. Strehovec

En la década de los años sesenta, Marshall McLuhan señalaba cómo la escritura había ejercido un gran peso en la conciencia del hombre, concibiendo un sujeto como entidad autónoma, inmóvil frente a la evanescencia de la palabra hablada. Las relaciones entre los registros oral y escrito siempre han conllevado una buena dosis de conflicto. Por un lado, parece evidente que vivimos en un contexto sociocultural en el que la palabra, escrita, se asocia a un tipo intelectual prestigiado y dominante. Por otro lado, la filología y la lingüística contemporánea se han encargado, durante las últimas décadas, de invertir esa jerarquía, señalando que el registro escrito no es más que un conjunto de convenciones socialmente aceptadas que intentan, siempre con un éxito parcial, reproducir la enorme vitalidad del registro oral (Mayans i Planells, 2002: 44).

Frente a esta dualidad establecida, y ya desdibujada, entre oralidad y escritura, la irrupción del ciberespacio conduce a una reformulación de estas nociones y al acto de observar, precisamente, el modo en que el Yo se ha revisitado a sí mismo, así como la clase de cultura (oral, escrita o tecnológica) que ha surgido asociada a estos nuevos paradigmas. La denominada por Pierre Lévy (1994: 256) cibercultura, o tecnociencia, y su ciberespacio, genera una evolución acelerada y caótica de la sociedad contemporánea. En este mundo de las tecnologías digitales, el conocimiento no está encerrado, sino que lo invade todo, se mediatiza, no es ya una pirámide estática sino colectiva que se propaga anárquicamente 
como un virus (W. Burroughs) o una metástasis (P. Lévy) ${ }^{1}$. La cibercultura reactualiza las palabras de McLuhan de modo que, como argumenta la ciberpoeta Giselle Beiguelman, "The médium does not count. In these days of nomadic words, the interface is the message" (2007: 103)².

La denominada por Ong Post-Tipography: Electronics (1982: 135) supone un movimiento de la conciencia a una nueva era de la que califica como "oralidad secundaria", en la que la palabra se ha mudado al ciberespacio. Esta oralidad secundaria, que Anxo Abuín remodela con el término "oralidad terciaria", que recibe de Gregory Ulmer (1994) y su término Electracy, evidencia sus parecidos con la primaria, incidiendo en su carácter social, en su inmediatez, convirtiendo a los oyentes en un grupo no homogéneo para diferenciarse de aquella en que "generates a sense for groups immeasurably larger than those of primary oral culture -McLuhan's "global village»" (Ong, 1982: 136). Abuín (2010: 5) se pregunta si podríamos aceptar el concepto de oralidad terciaria para referirnos a las obras nacidas a partir de esa irrupción de las nuevas tecnologías y dedica varias páginas de su artículo (2010: 6-8) a mencionar los paralelismos que halla entre las características que Walter Ong atribuye a la literatura oral para rastrearlas en los nuevos medios electrónicos. De este modo, el concepto "additive" de Ong (1982: 37) lo encuentra en la determinación de las lexias que conforman el lenguaje hipertextual, que permiten la coexistencia de varios niveles conceptuales, artísticos o culturales; el carácter "aggregative" (Ong 1982: 38) lo reconoce en el modelo rizomático y multilineal o multisecuencial que acompaña a las creaciones digitales; el elemento "redundant" (Ong 1982: 39) se refleja en la tendencia a la cita y a la intertextualidad de las obras electrónicas; su estatuto interactivo o "empathetic and participatory" de Ong (1982: 45) es evidente en la capacidad cocreadora del espectador-lector; y, finalmente, su función "situational" (Ong 1982: 49) se traslada al concepto de "tiempo real".

Si, como decía Ong, la escritura no puede prescindir nunca de la oralidad, los textos están hechos para que hablen y encierran un oralidad oculta (Havelock 1986: 76); tampoco puede hacerlo la ciberliteratura, que surge, desde mi punto de vista, como una disciplina que regresa a la oralidad y subvierte los espacios sistemáticos, rigurosos, lineales y ordenados de la escritura. Las tecnologías son máquinas memorísticas que ayudan a preservar el conocimiento, que potencian su espacialidad, su performatividad, a través de códigos multimedia, que conciben obras mutables y nómadas que no se acomodan a ninguno de los géneros clásicos, que encuentran su existencia, muchas veces, en su entidad abierta y fragmentaria, promoviendo la interactividad, la sociabilidad y el trabajo coral.

Partiremos de la concepción de que para que una obra sea oral debe contar con la intervención del oído, la imagen, el sonido o el ruido, la gestualidad,

\footnotetext{
${ }^{1}$ Este artículo se enmarca en el proyecto del Ministerio de Educación, Cultura y Deporte Narrativas cruzadas: hibridación, transmedia y performatividad en la era digital, dirigido por el profesor Anxo Abuín González. Referencia: FFI 2012-35296. Veremos como las performances poéticas de Laurie Anderson, como United States, utilizan canciones que se basan directamente en Burroughs, en obras como Let $X=X$ o Language is a Virus (Howell 1992: 24).

${ }^{2}$ Su página web es <http://www.desvirtual.com/info.htm>.
} 
la corporalidad y la voz para germinar y comprenderse. La voz, el pilar de la oralidad, sobrepasa la palabra, es palabra sin palabras, "es consciencia pero no habla ni piensa verdaderamente, simplemente trabaja para no decir nada" (Zumthor 1983: 13-14), es "logorrea" (Kruglanski 2007: 77) y logofagia (Blesa 1998). La voz es una facultas o "posibilidad simbólica ofrecida a la representación [...] que constituye en el transcurso de los siglos una herencia cultural transmitida (y 'traicionada') con, en y por el lenguaje y los otros códigos que el cuerpo humano elabora" (Zumthor 1983: 12). Por su parte, la poesía digital, o new media poetry, golpea al lenguaje y lo sacude trasladándolo hacia territorios de experiencia verbal que no habían sido vistos con anterioridad, a pesar de la larga tradición de poesía experimental, del modo en que existen ahora. El trabajo de los poetas digitales, como sostiene Eduardo Kac (2007: 11), guía al lenguaje más allá de los confines de la página impresa y explora una nueva sintaxis "made of linear and no-linear animation, hyperlinks, interactivity, real-time text generation, spatio-temporal discontinuities, self-similarity, synthetic spaces, immateriality, diagrammatic relations, visual tempo, multiple simultaneities, and many other innovative procedures".

Gran parte de los géneros de poesía digital se caracteriza por su carácter antimimético; como sostiene Jean Strehovec (2010: 70), en la línea de Zumthor, ni imita nada, ni dice nada, ni habla de nada, sino que promueve un evento lingüístico "in the 'artificial life of language', meaning it is rich also in terms of performance". Muchos de los textos de poesía digital están vacíos de contenido lógico, se recrean en la repetición, en la artificialidad de la forma y en los efectos sonoros ${ }^{3}$. Es el caso del grupo español Epimone (<www.epimone.net $>$ ), formado por Luis Calvo y Pedro Valdeolmillos, cuyo proyecto consiste en la creación de poemas que reiteran palabras en voz alta, a distinta velocidad, con variadas texturas y entonaciones para relevar su significado. La palabra que los poetas quieren que se repita una y otra vez es la de "creación" o "recreación". Cada efecto vibracional de los sonidos produce un impacto y cada uno de sus ecos se conecta con cada palabra que pronunciamos, cada sílaba se asocia a su significado eterno que "reverbera" en el aire (Williams 2003: 58). En muchas ocasiones, estas palabras se sitúan en el centro de la pantalla u ocupan distintas posiciones intercambiables, oscilando, superponiéndose, singularizándose por sus colores y por sus efectos sorpresivos; asumen, en ocasiones, la parte por el todo recurriendo al recurso de la metonimia que es muy representativo en la poesía digital: "in the digital medium the reader has access to the "whole" by activating a hypertext link". Es lo que Alexandra Saemmer denomina "the metonymic action of hyperlinks" (2010: 102-103).

Toda esta poesía digital, new media, es heredera de las conquistas formales de grupos y movimientos poéticos del siglo $\mathrm{xx}$, desde las aproximaciones racionales y antirracionales de los movimientos de Vanguardia de la primera mitad de siglo (Futurismo, Cubismo, Constructivismo, Dadaísmo y Letrismo), hasta los movimientos de la segunda mitad, como el Espacialismo, el Concretismo, $L=A=N=G=U=A=G=E$, Beat, Poesía visual, Fluxus o el Poema/Proceso (Kac 2007: 11).

\footnotetext{
${ }^{3}$ Vid. mis artículos titulados "La cultura digital en los Estudios literarios: Ciber/textual/especialidades poéticas" (2009) y "La hermenéutica en el ciberespacio: de William Gibson a Roman Ingarden" (2011).
} 
Recordemos como los poetas dadaístas, que constituyen un referente inexcusable en el campo de la poesía digital, exploraban aspectos sonoros como la simultaneidad y el ruidismo en una concepción múltiple del fenómeno poético que adoptaba como ingredientes básicos la danza, la performance, la música o la religión. Podríamos recuperar igualmente los trabajos de Francisco Cangiullo, pintor, escritor, performista y diseñador gráfico de los años veinte, adscrito al futurismo italiano, como su poesía pentagrammata, destinada a ser leída modulando la voz según las distintas marcaciones del pentagrama. Por otra parte, el concretismo paulista del grupo Noigrandes (Decio Pignatari y Augusto y Haroldo de Campos) valora la palabra en su dimensión lingüística, visual y fónica (en su verbivocovisualidad), con una naturaleza espacial que recurre a imágenes y espacios en blanco, rompiendo con las reglas sintácticas, atomizando y redistribuyendo las distintas partes del poema (Gache 2006: 17, 46-47, 127 y 133) .

La polipoesía, cuyo conocido manifiesto aparece por vez primera en el ensayo "Polipoesia, dalla lectura alla performance di poesia sonora", dentro del catálogo Visioni, Violazioni, Vivisezioni, en marzo de 1983, encuentra un gran desarrollo en el contexto posmoderno, como balanza y equilibrada mezcla de diversos lenguajes, priorizando la poesía sonora como guía de los demás lenguajes propios del espectáculo.

El género hunde sus raíces en la fenomenología de Husserl y su intencionalidad se dirige a la primacía de lo oral, porque tal poema "está pensado-concebido-realizado en función de lo real, y teniendo en cuenta el grado de conciencia con que el poeta llega a esta elección, en otras palabras, es necesario sentir la urgencia, la esencia indispensable de la trasmisión oral" (Minarelli 1987). El manifiesto de polipoesía condensaba en seis principios básicos la concepción que Minarelli poseía con respecto a la suma de poesía, oralidad y nuevos medios. El primero de ellos incide en que el avance de la poesía sonora se conseguirá únicamente por el desarrollo de las nuevas tecnologías, los medios electrónicos y el ordenador. La segunda característica es que la palabra, la voz, se convierten en el objeto de experimentación de los polipoetas para liberar su sonoridad. En este sentido, y es el tercer principio, la elaboración del sonido no admite límites, ligándose con el ruidismo. Todo ello se sitúa en un tiempo (cuarto aspecto) recuperado por su sensibilidad, que queda sometido al montaje. El quinto rasgo insiste en el carácter rítmico de la lengua y, por último, la polipoesía es imaginada y realizada para el espectáculo en vivo, sus fuentes son la poesía sonora, la musicalidad, la mímica, el gesto, la danza, la imagen, la luz, el espacio, los vestidos y los objetos (Minarelli 1987) .

En los años noventa adquiere un gran impacto la presentación en el Centro George Pompidou de las Tres mitologías de un poeta ciego del poeta que acuña el concepto de poesía combinatoria, J. P. Balpe. Trois mythologies et un poète aveugle fue una creación acústica y musical, presentada el 14 de noviembre de 1997 y suponía un diálogo en tiempo real entre un autómata de generación de poemas,

\footnotetext{
${ }^{4} \mathrm{Y}$ en los años cincuenta encontramos producciones como los poemas estocásticos de Theo Luz, en los sesenta, los trabajos de Nanni Balestrini, con su Tape Mark 1 (1961), los poemas electrónicos del grupo Fluxus, con Emmett Williams.
} 
elaborado por el poeta Jean Pierre Balpe y un autómata de generación musical, concebido por Jacopo Baboni Schilingi. Mediante la puesta en escena de Gérard Assayag, el grupo constituido por tres poetas, los lectores, un pianista, un percusionista y una soprano, generaban una y otra vez un sinnúmero de textos, a partir de las proposiciones de dos autómatas, atendiendo al estilo del poeta ciego, al de Balpe, al de Henri Deluy y al de Joseph Guglielmi. En este intercambio oral, el lenguaje adquiere el poder de exorcismo, con el diálogo, a veces sordo, "autista", dice Gache (2006: 199), de los ordenadores.

En los márgenes del siglo $\mathrm{xx}$, y continuando los planteamientos de la polipoesía para combinarla con las nuevas tecnologías, ejerce su creatividad el artista español Xavier Sabater ${ }^{5}$. En "Susurros de invierno", un poema elaborado de la mano del realizador argentino Gonzalo Marcuzzi Iglesias, se nos presenta un ciberpoema que es una mezcla de rasgos de la poesía underground, social, oral, sonora, fonética, electrónica, visual, polipoesía y vídeo poesía ${ }^{6}$. Si accedemos a su reproducción en el canal DocuMentalidades, oímos, y vemos, al poeta recitando el texto, mientras que se proyectan a su espalda, detrás de sus ojos, vídeos muy rápidos sobre contenidos dispares y, de vez en cuando, se ven reflejadas en la pantalla ciertas palabras del poema. Al mismo tiempo, el poema está acompañado de sonido y música procedente de una fuente externa, como la radio, o de una voz en off que usa otras lenguas para sumarlas al español. El poema termina, aunque se prolonga de forma acústica, con el sonido interminable de un tocadiscos sin vinilo.

Otro de sus poemas, "IncoHerencia", un vídeo poema realizado en 2006 con Marcuzzi, a partir de otro texto de Jacobo Sucari, se convierte en un poema fonético trabajado con un procesador de efectos aplicado a la voz, y acompasado con la música del chileno Maxi y el montaje nuevamente de Marcuzzi.

La poesía digital es en sí misma un género que aúna las tradiciones de la Vanguardia y Neovanguardia, la poesía visual y concreta, las vídeo instalaciones artísticas, el arte conceptual, el Net Art, el Software Art, y subgéneros como la poesía cinética y animada, la poesía ergódica (siguiendo la terminología de Espen Aarseth), la visual digital, la digital sonora (digital sound poetry), la interactive

\footnotetext{
5 <http://www.cyberpoem.com/poets/sabater.htm>. Sabater ha publicado una colaboración en la que enumera los principales seguidores españoles de la polipoesía. Se refiere a nombres como Albert Subirats, Antón Ignorant, Carlos Romero, Enric Casassas, Jordi Pope, Josep Ramón Roig, Carles Hac Mor, Xavier Canals, J. M. Calleja, Rosa Grau, Flautus Voicis Trí, Poliphonética Dinámica y otras agrupaciones, como el Laboratorio Informal de Actividades Diversas, la Sección de Investigaciones Sin Sentido, II-logic Art Company y LA PAPA (Performers, Artistas y Poetas Asociados), Accidents Polipoètics (<http://usuarios.multimania.es/accidents/>), Human Trash + La Pubilla Daltònica: Polipoesia-clown / cabaret literario, Poliposeídas: Projectes Poètics sense Títol: Festival Experimenta Club. Destaca igualmente la labor de otros poetas que, si bien no se acercan tanto al campo de la polipoesía, su labor puede confundirse con ella: Javier Maderuelo, Carles Santos, Anna Ricci, Fernando Millán, Llorenç Barber y Bartolomé Ferrando. Podemos señalar también la influencia de la polipoesía en R. Kostelanetz, Diamanda Galas, Lydia Lunch, Larry Wendt, Tracy Splinter, Mark Sutherland, los franceses Gerard Jacquet, Bernard Heidsieck, Christian Prigent o Nathalie Quintana, los portugueses Fernando Aguiar o el grupo lisboeta Copo, el poeta ruso Valeri Scherstjanoi, los japoneses Nobuo Kubota, Suzuki Takeo y Seiji Shimoda, o el brasileño Philadelpho Menezes (<http://www.poesiavisual.com.ar>).

${ }^{6}<$ http://www.dalealplay.com/informaciondecontenido.php?con=13504>.
} 
poetry, la code poetry, los generadores de poesía (poetry generators), así como los digital textscapes e instalaciones con las performances poéticas (Strehovec 2003).

De este modo, y tal y como adelantábamos, a día de hoy, en la trayectoria marcada por todos estos creadores, que desemboca en la poesía digital, multimedia, electrónica o performativa, ya no se mantiene la contraposición de los universos semántico verbal, visual y sonoro, en un deseo de romper con los determinismos del lenguaje. Las obras digitales, y en especial las poéticas, combinan distintos sistemas semióticos, provocan una contaminación entre ellos y ponen en paralelo lo lingüístico, con lo visual y lo fónico. Se trata de un proceso que Gunther Kress calificó de sinestésico: "A new theory of semiosis will have to acknowledge and account for the processes of synaesthesia, the transduction of meaning from one semiotic mode in meaning to another semiotic mode" (1998: 76).

La oralidad de los medios electrónicos mueve a la acción, es una "Ilamada, un grito", una transacción interpersonal, una explicación, interpretación o hermenéutica de un interlocutor hacia otro u otros (Ong 1988: 267), es un espectáculo acústico, visual y hablado, un talk show (Havelock 1986: 63), un Speech act (Ong 1995) que deja abiertas las puertas mediante su fluidez, como sostiene J. D. Bolter (1991), a una constante revisión. Se desarrolla, así, una nueva hermenéutica de los textos electrónicos que debe tener en cuenta no solo la palabra, sino también la imagen, los gráficos, el sonido, la proxémica y la quinésica: "the texts [...] have been transformed into kinetic textscapes with an emphasis on visuality (and tactility), for which the main purpose is to attract a hybrid reader-listener-viewer as a voyeur" (Strehovec 2010: 4)

Esta es la hermenéutica que debemos aplicar, por ejemplo, a la Action Poetry que enfatiza la noción de "nomadismo" como una parte importante del trabajo de los actores-poetas. En ella, el cuerpo se convierte en un vehículo de transmisión expresiva en el que la espacialidad adquiere resonancias clave. La Action Poetry suma el arte visual, las instalaciones multimedia y la "living body poetry", recuperando un cierto componente de rito a través de la sonoridad y la danza (Frangione 2006)

Los nuevos medios resultan una mezcla entre las convenciones culturales más antiguas de representación, acceso y manipulación del conocimiento y las convenciones más modernas de los mismos procesos. En palabras de Lev Manovich, "The 'old' data are representations of visual reality and human experience, i.e., images, text-based and audio-visual narratives-what we normally understand by 'culture'. The 'new' data is numerical data. As a result of this mix, we get such strange hybrid as clickable 'image-maps', navigable landscapes of financial data, QuickTime [...], animated icons [...], and so on" (2003: 19). La cultura electrónica, visual, digital, en fin, conjuga elementos orales y escritos, literarios o no literarios, "exploding the reductionist arguments sometimes posited in oral/ literate dichotomies" (Mason 1998: 307) ${ }^{7}$.

\footnotetext{
7 En el terreno de la poesía digital destacan los certámenes de la E-Poetry, que tienen lugar desde 2003. En cuanto a los dedicados estrictamente a la poesía oral sobresale el más antiguo de todos: Poliphonix, celebrado de forma itinerante en diversos lugares del mundo, el Festival de Polipoesía
} 
Las obras digitales son obras espaciales liberadas por la voz, son mutables y fluyen como performance, escapan al tiempo, que se vuelve reversible. El tiempo es policrónico, un viaje que se va haciendo, "not by the view or the path, but by the changing of the view, the diverging of the path; not by the archive or database, but by the ever re-contextualized act of retrieval. It is, then, not stasis, not velocity, but a new sort of time connection: what speeds me up, what slows me down, what hangs (Strickland 2007: 26).

Por su calidad de orales, además de visuales y auditivas (multimedia, en definitiva) nunca son exactamente repetibles, se refrescan continuamente. La performance es la acción compleja por la que un mensaje poético es simultáneamente transmitido y percibido, aquí y ahora, por un enunciador y un destinatario, en unas circunstancias compartidas, haciendo coincidir los dos ejes de la comunicación social: "el que une el locutor al autor y aquel por el que se unen situación y tradición" (Zumthor 1983: 33). En la poesía digital y performativa el oyente también crea la forma de la obra, puesto que su cometido es igual de importante que el del intérprete. Se convierte, como sostiene el poeta electrónico Ph. Bootz, en un "reader as "en jeu»" (2010: 25), puesto que las actividades del "autor" y del "lector" han sufrido un desplazamiento, un giro, un loop, de modo que el lector ya no es solo aquella figura a la que se dirige la obra, sino su coautor, a pesar de las limitaciones que necesariamente puede tener. Esta confrontación del lectorespectador con sus constricciones es lo que Bootz denomina "ritual work" (2010: 20).

Veamos tres ejemplos.

Muchos de los modelos de poesía digital y performativa, como los de Cin Salach, se acercan a la cultura popular de la poesía oral. Su poesía, como la de Laurie Anderson o Hedwig Gorski ${ }^{8}$, se asocia al ritmo, lo respiratorio, la acción, la actitud, el movimiento, la idea de cuerpo, de performance, encuadrándose en una oralidad mediatizada, diferida en el tiempo y en el espacio (Zumthor 1983: $37)^{9}$. Cin Salach, poeta multimedia desde 1987, se singulariza por su creación del Loofah Method, una conjugación de spoken word, poesía, percusión y teatro que se asoció al compositor y músico Mark Messing, en un primer momento, y a Sue Walsh y Kurt Heintz, en un segundo, para poder trabajar con la fotografía y el vídeo. Una de las primeras obras del grupo fue estrenada en 1989 e incorporaba performance art, danza, música, cine, imágenes generadas por ordenador, sonido y vídeo. A partir del Loofah Method, desaparecido en 1995, Salach da origen a la Bob Shakespeare Band, junto con Sheila Donohue, Kendall Dunkleberg o Marc Smith hasta llegar, solo con Donohue, al dúo Betty's Mouth. Ya en los años noventa, Salach crea Ten Tongues, en el que recupera a miembros del Loofah

de Barcelona, Intersignos de Brasil, Yuxtaposiciones de Madrid, el Festival de Polipoesia de Bolonia, Bobeobi de Berlín o el ya desaparecido Proposta de Barcelona.

8 <https://sites.google.com/site/hedwiggorskisite/>.

9 Podríamos destacar igualmente otros nombres dentro de la Performance Poetry, como los de Marc Smith, Dwight Okita, Jean Howard, Morgan McCabe, Jeff Crissman, Tattoo Taboo y John Giorno, que creó la Environment Poetry y fue uno de los primeros autores en combinar poesía y performance. 
Method para experimentar más con lo acústico, en detrimento de los programas tecnológicos.

La artista estadounidense Laurie Anderson, que se autonomina como "Storyteller" (Howell 1992: 9), constituye uno de los ejemplos más representativos de Performance Poetry mediante la utilización de un instrumental muy variado, en el que su cuerpo se convierte en la principal herramienta y su voz en el vehículo que encauza sus reinvindicaciones de "resistencia" frente al sistema político, social y cultural establecido. Se ha interpretado su trabajo como un salto de la creación individual, autónoma, en soledad y autoritaria, a ese trabajo coral que mencionábamos líneas atrás y que remite al ejercicio de una enunciación colectiva. La definición que Birringer proporciona de Anderson describe la identidad desdibujada de una artista "displaced and delayed: like the vocal 'delays' and electronic distortions of her voice, her own body and gender identity are set afloat in the multitrack audiovisual 'choreography' to which she (ironically) refers as the 'Language of the Future' in Part I of United States" (Birringer 1993: 222). La labor de Anderson combina, una vez más, un ejercicio multimedia en el que la tecnología supone una reformulación de la cultura basada en el concepto de "mediación":

But the interesting is that Anderson has an ambiguous relationship to technology. Through technology, she mimes the process of mediation itself, as Auslander observes, "through her manipulation of communication technologies, she addresses many issues, including gender representations, and the social implications of our mediatized environment. (Gonçalves s.a.)

Lo más característico de Laurie Anderson es la distorsión de su voz mediante los elementos electrónicos para duplicarse en sus dobles, en sus dummies (Mackenzie, 1997), creando nuevos personajes que ya no le pertenecen, los sonidos especiales que emiten sus instrumentos, así como el tratamiento digital de las imágenes que se proyectan a su espalda. En la obra de Anderson, la tecnología es el elemento estético que se vincula siempre con el lenguaje por lo que, como ha estudiado F. Gonçalves (2005: 194), sus instalaciones y performances se crean a partir de la relación que surge con los dispositivos técnicos, que producen un efecto estético y, sobre todo, hacen sobresalir ciertas condiciones del discurso.

Hedwig Gorski, por último, reaviva el término Performance Poetry para describir su trabajo oral, grabado en directo mientras actúa. Uno de sus últimos libros, Intoxication: Heathcliff on Powell Street (2009), es un archivo/memoria de su teatro experimental de los años setenta, una obra titulada Booby, Mama!, calificada como "a cut-up neo-verse drama", precursora de la Performance Poetry y del Slam. Otra de sus obras es el radio drama Thirteen Donuts, un tributo a los inmigrantes polacos en New Orleans. La artista-poeta-performer se proclama heredera de arte conceptual y la poesía Beat y de autores específicos como Mayakovsky, Khlebnikov, Warhol, Philip Glass, John Cage o Jim Jarmusch.

La inmediatez y procesualidad de la obra performativa se refleja en su estado irrepetible:

... un acto único, fugitivo, irreversible... e individual, ya que se puede dudar de que la misma performance se viva de manera idéntica por dos oyentes. [...] El 
oyente, como el lector enfrentado al libro, desde que acepta el riesgo, se implica en una interpretación cuya perfección nadie le asegura. Pero más que el lector, su sitio es inestable: ¿oyente?, ¿narrador? En el seno de las costumbres orales, las funciones tienden sin cesar a intercambiarse. (Zumthor 1983: 240)

La obra digital tiene sus propios códigos, sus algoritmos, su "performative life" (Turkle 2004: 6), su "codexspace" (Cayley 2007: 105-125). Podríamos mencionar, por ejemplo, el caso de los chats, como estudia B. L. Mason, o de los Muds (vid. Janet Murray o Sherry Turkle), los sms, en los que son necesarios unos pocos caracteres para indicar la totalidad de la conversación. La escritura se ha subvertido, la puntuación se transforma en emoticones, las mayúsculas se tambalean en la pantalla y emiten sonidos o ruidos, las líneas, las frases y los párrafos se convierten en opcionales, por lo que el concepto de texto escrito, rígido y estable, se convierte en un Text Escape, una fuga textual. Con los hipertextos, los blogs o los transmedia se produce, en palabras de Alexandra Saemmer, una "new semantic proximity, maybe even a faithful translation, between words and images", en la que la palabra adquiere nuevas cualidades gráficas, es transportada a nuevos estadios y adquiere una nueva "aura" (2010: 94-95).

Manejamos textos de varias dimensiones que oponen distintas formas de expresión, como la imagen fija, la imagen animada, el sonido, las simulaciones interactivas, las cartas interactivas, los sistemas periciales, las ideografías dinámicas, las realidades virtuales o las vías artificiales. Pierre Lévy, exponente de la cibercultura, crea el neologismo cosmopedia para referirse al nuevo tipo de organización de los saberes, asentado en las posibilidades que ofrece la informática para la gestión de conocimientos. La cosmopedia es un espacio multidimensional de representaciones dinámicas e interactivas y supone una confrontación de imagen y texto, sea escrito, oral, o una mezcla de los dos. Porque esta cosmopedia desmaterializa las separaciones entre los saberes, disuelve las diferencias entre especialidades para permitir la pervivencia de las zonas fronterizas difusas, creando una topología continua y dinámica (Lévy 1994: 260-262).

Como comentábamos líneas atrás, los textos de la cultura visual digital son movedizos y nómadas-orales y conciben el tiempo según unos esquemas circulares y el espacio como la dimensión de un nomadismo" (Zumthor 1983: 36). Podríamos mencionar los poemas nomádicos de Giselle Beiguelman, para dispositivos móviles, PDAs y paneles electrónicos, como Wop Art (2001), Leste o Leste? (Did You Read the Easts? (2002) o Poétrica (2003). Estos proyectos persiguen constituirse en ejemplo de la cultura híbrida, combinando lo escrito, con lo posfonético-oral. Para Beiguelman estas son las características que definen sus creaciones:

The place where the text is located is the reader's non-place, space-time of antiphenomenology and visibility. [...]

Nothing imprisons the text. The prefiguration of writing is always a sordic act, a vile exercise, a mere waste of time within a reading interval.

Interfaces are primordial environments of the arbitrariness of enacted words, betraying language so as to become language. (Beiguelman 2007: 97) 
Debido a su estado "en construcción" y a su ansia de transgredir la tradición, ya que las aspiraciones textuales de los autores ya no pueden realizarse físicamente en la página impresa, gracias a su deseo de hacerse fiel reflejo del desorden del mundo que nos rodea, son textos que mezclan los géneros, casi como una revitalización de las ideas románticas, tecnorrománticas, como las han calificado Dioniso Cañas y Carlos González Tardón (2010). Se produce una indefinición fronteriza entre oralidad/escritura/multimedia, una ruptura genérica que no es nueva.

La ciberpoesía conjuga géneros muy diversos, más próximos al Net Art, al Software Art, o al Browser Art, que a la literatura impresa (Strehovec 2010: 68), revitaliza el acto de consumo literario, a veces aminorado por la ausencia de un público lector que ha apartado la lectura de libros escritos a un segundo plano porque está más familiarizado con los ordenadores personales, los móviles o los ipads. La poesía digital se ha vuelto, como el slam, una cultura de club: "That digital poetry can be, in an absolutely adequate manner, represented in clubs and not necessarily inside rooms asigned to the elite culture (libraries, university classrooms, cultural centers, etc.)" (Strehovec 2010: 68).

Y esta brevedad es constitutiva igualmente de la cultura visual digital. Las obras se vuelven instantáneas, rápidas, intensas y repentinas por la condensación de sus palabras, se tornan minimalistas, como podemos observar, por último, en The Book of the Dead de Xavier Malbreil y Gerard Dalmon ${ }^{10}$.

El saber de la comunidad virtual es ahora colectivo, imposible de reunir en un solo cuerpo (Lévy 1994: 259), es un sujeto abierto a otros miembros, a otros colectivos, a nuevos aprendizajes, que no dejan de componerse y descomponerse, de nomadizarse (una vez más) en el espacio del saber y de la pantalla.

\section{OBRAS CITADAS}

Aarseth, Espen (1997): Cybertexts. Perspectives on Ergodic Literature. Baltimore/Londres, The John Hopkins University Press.

Abuín González, Anxo (2010): "Espaces acoustiques, textures sonores: Oralité tertiaire et langages électroniques". En: Recherche Littéraire/Literary Research, vol. 26, n. ${ }^{\circ} 51-$ 52, pp. 3- 14.

Accidents Polipoètics (1992): Accidents Polipoètics. Urgell, Dentro di me. (1997): Más triste es robar. Barcelona, Del Khan.

(2003): Todos tenemos razón. Barcelona, La Tempestad.

Auslander, Philip (1992): Presence and Resistance: Postmodernism and Cultural Politics in Contemporary American Performance. Michigan, The University of Michigan Press. Balpe, Jean Pierre (s. a.): Rencontres Medias 1 (1996-1997). Aspects des nouvelles technologies de l'information. París, BPI en Actes, pp. 145-163.

Beiguelman, Giselle (2007): "Nomadic Poems". En: Media Poetry. An International Anthology. Chicago, The University of Chicago Press, pp. 97-103.

\footnotetext{
10 Puede leerse un análisis de esta obra en Luiz dos Santos (2010: 84-92).
} 
Birringer, Johannes (1993): Thetre, Theory, Postmodernism. Bloomington, Indiana University Press.

Blesa, Túa (1998): Logofagias. Los trazos del silencio. Zaragoza, Universidad de Zaragoza.

Bolter, Jay David (1991): Writing Space. The Computer, Hypertext and the History of Writing. Hillsdale (New Jersey), Lawrence Erlbaum Associates.

Bootz, Philippe (2010): "The Unsatisfied Reading". En: Bootz, Philippe y Baldwin, Sandy (eds.) (2010): Regards croisés. Perspectives on Digital Literature. Morgantown, West Virginia University Press, pp. 11-25.

Cañas, Dionisio y González Tardón, Carlos (2010): ¿Puede un computador escribir un poema de amor?: tecnorromanticismo y poesía electrónica . Madrid, Devenir. Cayley, John (2007): "Beyond Codexspace: Potentialities of Literary Cybertext". En: Media Poetry. An International Anthology. Chicago, The University of Chicago Press, pp. 105-125.

Frangione, Nicola (2006): "Performance Art and Action Poetry - beyond work of Art plural". En: <http://performancelogia.blogspot.com/2007/04/poesa-y-performance.html>. Gache, Belén (2006): Escrituras Nómades. Gijón, Trea.

Gonçalves, Fernando (2005): "Laurie Anderson e as apropiações estéticas da mídia e da tecnologia na arte da performance". En: Comunicação, Mídia e Consumo, vol. 2, n. ${ }^{\circ}$ 4, pp. 183-193. Disponible en <http://www.revistas.univerciencia.org/index.php/ comunicacaomidiaeconsumo/article/view/5130/4749>.

Gonçalves, Fernando (s. a.): "Performing the Trojan Horse: Laurie Anderson's strategies of resistance and the "postmedia era»". En: <http://people.brunel.ac.uk/bst/2no2/ Papers/Fernando Performing\%20the\%20Trojan\%20Horse.htm>.

Havelock, Eric A. (1986): The Muse Lerans to Write. Reflections on Orality and Literacy from Antiquity to the Present. New Haven / Londres, Yale University Press. Traducción al castellano de Luis Bredlow Wenda: La musa aprende a escribir. Reflexiones sobre oralidad y escritura desde la Antigüedad hasta el presente. Barcelona, Paidós, 1996.

Howell, John (ed.) (1992): Laurie Anderson. Nueva York, Balliet \& Fitzgerald Inc.

Kac, Eduardo (2007): Media Poetry. An International Anthology. Chicago, The University of Chicago Press.

Kress, Gunther (1998): "Emerging Literacies. Visual and Verbal Modes of Representation in electronically mediated communication: the potentials of new forms of text". En: Ilana Snyder (ed.): Page to Screen. Taking Literacy into the Electronic Era. Londres / Nueva York, Routledge, pp. 53-79.

Kruglanski, Orit (2007): "Interactive Poems". En: Media Poetry. An International Anthology. Chicago, The University of Chicago Press, pp. 77-84.

Lévy, Pierre (1994): L'intelligence collective. Pour une anthropologie du cyberspace. París, La Découverte. Traducción al portugués de Fátima Leal Gaspar y Carlos Gaspar: A Inteligência Colectiva. Para uma Antropologia do Ciberespaço. Lisboa, Instituto Piaget, 1994.

(1997): Cyberculture. Rapport au Conseil de l'Europe dans le cadre du projet "Nouvelles technologies: cooperation culturelle et communication". París, Éditions Odile Jacob / Édts. du Conseil de l'Europe. 
Luiz dos Santos, Alckmar (2010): "How to read words in Digital Literature". En: Philippe Bootz y Sandy Baldwin (eds.): Regards croisés. Perspectives on Digital Literature. Morgantown, West Virginia University Press, pp. 84-90.

Mackenzie, Jon (1997): "Laurie Anderson for Dummies". En: The Drama Review, vol. 41, n. ${ }^{\circ}$ 2, pp. 30-50.

Manovich, Lev (2003): "New Media from Borges to HTML". En: Noah Wardif-Fruin and Nick Montfort (ed.): The New Media Reader. Cambridge-Massachusetts, The MIT Press, pp. 13-25.

Mason, Bruce Lionel (1998): "E-Texts: The Orality and Literacy Issue Revisited". En: Oral Tradition, vol. 13, n. ${ }^{\circ}$, pp. 306-329.

Mayans i Planells, Joan (2002): Género Chat o cómo la etnografía puso un pie en el ciberespacio. Barcelona, Gedisa.

Minarelli, Enzo (1987): Tramesa d'Art, Valencia. Disponible en <http://www.3vitre.it/index. html>.

Ong, Walter J. (1982): Orality and Literacy. The Technologizing of the Word. Traducción al castellano de Angélica Scherp: Oralidad y escritura: tecnologías de la palabra. México, FCE, 2009.

(1988): "Before Textuality: Orality and Interpretation". En: Oral Tradition, vol. 3, n. ${ }^{\circ}$ 3, pp. 259-269.

(1995): "Hermeneutic Forever: Voice, Text, Digitization, and the «|»". En: Oral Tradition, vol. 10, n. ${ }^{\circ} 1$, pp. 3-26.

Sabater, Xavier (1992): Polipoesia. Primera Antologia. Barcelona, Sabater Edicions.

Saemmer, Alexandra (2010): "Textual material in the Digital Medium". En: Philippe Bootz y Sandy Baldwin (eds.): Regards croisés. Perspectives on Digital Literature. Morgantown, West Virginia University Press, pp. 93-104.

Strehovec, Janez (2003): "Text as a loop: On the digital Poetry". Melbourne, DAC. Disponible en http://www.hypertext.rmit.edu.au/dac/papers/Strehovec.pdf.

(2010): "Digital Poetry beyond the metaphysics of «Projective Saying»". En: Philippe Bootz y Sandy Baldwin (eds.): Regards croisés. Perspectives on Digital Literature. Morgantown, West Virginia University Press, pp. 63-76.

Strickland, Stephanie (2007): "Quantum Poetics: Six Thoughts". En: Eduardo Kac (ed.): Media Poetry. An International Anthology. Chicago, The University of Chicago Press, pp. 25-44.

Turkle, Sherry (2004): "Collaborative Selves, Collaborative Worlds: Identity in the Information Age". En: James A. Inman, Cheryl Reed y Peter Sands (eds.): Electronic Collaboration in the Humanities. Issues and Options. Mahwah/New Jersey/Londres, Lawrence Erlbaum Associates, pp. 3-12.

Ulmer, Gregory L. (1994): Heuretics. The Logic of Invention. Baltimore, The John Hopkins University Press.

Vilariño Picos, María Teresa (2009): "La cultura digital en los Estudios literarios: Ciber/textual/especialidades poéticas". En: Amelia Sanz Cabrerizo (ed.): Teoría Española con voz propia (Homenaje a José Antonio Mayoral). Madrid: Arco Libros, pp. 235-261. (2011): "La Hermenéutica en el ciberespacio: de William Gibson a Roman Ingarden". En: Ámbitos, n. ${ }^{\circ} 25$, pp. 87-98. 
Williams, Saul (2003): "The Future of Language". En: Mark Eleveld (ed.): The Spoken Word Revolution (Slam, Hip Hop \& the Poetry of a New Generation). Naperville: Sourcebooks, pp. 58-60.

Zumthor, Paul (1983): Introduction à la poesie orale. París, Éditions du Seuil. Traducción al castellano de Ma Concepción García-Lomas: Introducción a la poesía oral. Madrid, Taurus-Alfaguara, 1991. 